involved; and (2) the surgeon's familiarity not only with the region in which he is working but also with the many technical details of intranasal manipulation and operation. The maxillary antrum may be operated upon and subjected to very considerable traumatism without any appreciable risk because it is far removed from any vital stru:tures. $Q$ aite the reverse holds in the case of the higher sinuses and many fatal results have occurred as a direct result of operative interference. These "regrettable occurrences " have generally followed radical procedures upon the fronto ethmoidal sinuses and in nearly all the cases which $I$ have been able to investigate (including two of my own) the cause of failure may be summed up in two words-viz., deficient drainage.

After having given a fair trial to the many methods which have been advocated for the treatment of chronic empyema of the fronto-ethmoidal sinuses, $\mathrm{I}$ am in entire accord with those who maintain that only complete obliteration or destruction of the bony cavities offers any prospect of a permanent radical cure. In the case of the frontal sinus the anterior bony wall should be entirely removed and any recesses of the sinus thrown into the main cavity by the breaking down of partition walls. Especially will this be necessary in those instances where certain suppurating ethmoidal cells extend outwards immediately below the floor of the frontal sinus and are only separated from it by a thin, almost transparent septum of bone. Furthermore, the fronto-nasal canal must be enlarged and suppurating anterior ethmoid cells in its immediate neighbourhood must be carefully broken down or reinfection of the higher sinus will occur. Having proceeded thus far the latter cavity should be lightly packed with sterilised gauze which cun be changed on alternatg days until the obliteration of the sinus by granulation tissue is complete. From the moment the operation is completed the motto of the surgeon must be, "Free, unhindered, spontaneous dr uinage," and if he secures this he need never fear that any serious harm will come to his patient.

The treatment of ethmoidal and sphenoidal suppurations will demand from the surgeon a practical familiarity with intranasal operations and technique and without having acquired these he and his patient will probably be disappointed with the result of surgical intervention. Generally speaking, operative manipulations in the ethmoidal region will be safe when they are carried out below the level of insertion of the middle turbinal bone and much excellent information may be gained as to the progress one is making by the frequent examination of the diseased area with the tip of the little finger passed upwards through the nostril. In this way the limit between soft chronically inflamed (rarefying osteitis) and firm healthy bone can often be ascertained. In most operations upon the ethmoidal (and frontal) sinuses it will be a great advantage to remove at least the anterior half of the middle turbinal bone as a preliminary procedure not only because it is often itself chronically inflamed but the absence of this structure will enable the surgeon to deal more easily with the lateral mass of cells and free drainage will be secured during the after-treatment. A dangerous area is reached when instruments are used above the level already mentioned, for here we are in close proximity to the cribriform plate.

The sphenoidal sinus is best reached through the nasal cavity and it will nearly always be necessary first to remove the middle turbinal bone. In dealing with this deep-seated sinus the surgeon must make use of a bright reflected light and thoroughly define the anterior sinus wall and its ostium before he commences removal of the same. Operaticn ; upon this sinus and the posterior ethmoidal cells are best carried out under the influence of cocaine (20 per cent.) anæsthesia, and the most suitable instruments for breaking down the thin bony structures in these regions are Hajek's series of hooks. The inside of the sphenoidal sinus should never be curetted, for if a large opening be made in the anterior wall suppuration will generally cease if the cavity be frequently cleansed with mild antiseptic lotions. Curettage of the inside of the sinus, and especially of its upper and outer walls, may prove to be a very dangerous procedure. Those who have had much experience in operating upon the sinus will agree that it is much easier of approach than would at first thought seem probable. The opening in its anterior wall should always be made as large as possible, for it exhibits a very marked tendency to contract.

From what has preceded it must, I think, be conceded that there is no mystery in the surgical treatment of the suppurative lesions of the nasal accessory sinuses. On the contrary, only in so far as the surgeon bases his treatment on the fundamental principles of surgery can he look for a successful result of his intervention. In one sense only can the subject be regarded as "specialised" and that is in the matter of the technique which is rendered necessary by the peculiar anatomical and physiological characteristics of the regions themselves. For these reasons a variety of special instraments and methods of examination are absolutely essential. If, however, the surgeon can spare sufficient time for perfecting himself in the manipulations necessary for the investigation of the diseases of the nasal accessory sinuses the resulting advantages should be threefold-viz., to the surgeon himself will be opened up a subject of fascinating interest and of great possibilities, to the patient will the prospect of relief from suffering be enhanced, while surgery will continue in no small degree the advancement of its science and art.

\section{NOTE ON THE VALUE OF HOT-WATER INJECTIONS AS A SUBSTITUTE FOR NUTRIENT ENEMATA IN THE TREATMENT OF GASTRIC ULCER.}

By W. PASTEUR, M.D., F.R.C.P. LOND., PHYSICIAN TO ThE MIDDLESEX HOSPITAL AND CONSULTING PHYSICIAN TO THE NORTH-EASTERN HOSPITAL FOR CHILDREN.

For the last 18 months I have treated all cases of gastric ulcer requiring rectal feeding by enemata of plain water at the temperature of the body with results sufficiently uniform and satisfactory to be worth recording. I do not propose to discuss the indications for rectal feeding but rather to compare the results obtained when plain water is used instead of beef-tea, milk, eggs, starch, and the many other foodstuffs which are employed in concocting the four- or six-ounce enema which has become consecrated by usage in the treatment of these cases.

It is generally held that the rectum is capable of absorbing well (1) peptone; (2) white of egg, especially with salt added; (3) raw beef juice; and (4) starch and sugar and, to a far less extent, milk proteids and gelatin. It is also common knowledge that patients can be kept alive by this method of alimentation in comparative comfort for several weeks. But the comfort is only comparative. R lief from gastric pain and vomiting is usually prompt, but very soon other symptoms, attributable mainly to the rectal feeding, make their appearance. Of these the first to arise and the most important is thirst. Nor is this surprising seeing that the total amount of fluid given per rectum in the 24 hours varies from 16 to 40 ounces at the outside. It is usual to relieve thirst by allowing the patient to sip a small quantity of hot water from time to time, or to suck ice, or from half a pint to a pint of warm water is injected into the rectum once or twice in the 24 hours. This last method is the best but it has the drawback of increasing the total number of enemata and thereby the risk of rectal intolerance.

Ice by the mouth should, in my opinion, always be avoided. It often fails to quench the thirst and it is difficalt to limit the amount taken. I have long since given up the use of ice in the treatment of gastric nlcer except in an icebag over the epigastrium, suspended from a cradle so as to insure the lightest possible contact, for the relief of pain. Sipping hot water undoubtedly relieves thirst in some cases, but as the primary object in the treatment of this condition is, so far as possible, to secure physiological rest for the stomach, I think this is best achieved by giving nothing whatever by the mouth for the first few days, at all events, and this can only be done by administering a sufficient quantity of water per rectum to prevent thirst from becoming urgent.

Another symptom which occurs in the course of a few days, I believe in all cases where the enemata contain beef-tea, is an unpleasant taste of beef-tea in the mouth not infrequently associated with a feeling of nausea. This symptom is sometimes very distressing.

By substitating ten-ounce enemata of plain water at a temperature of $100^{\circ} \mathrm{F}$. for the smaller nutrient enema at present in general use it is possible to prevent thirst altogether in the great majority of cases and to do away entirely with the unpleasant taste in the mouth. 
I am informed by my ward sister, to whose careful obserFations I am largely indebted, that since we have adopted the plain-water enemata the patients have been altogether more comfortable and much easier to manage than under the old régime of small nutrient enemata. I am quite satisfied that the general condition of the patients is at least as good, if not better, and that recovery takes place as quickly, and I may add that since I first adopted this treatment in November, 1902, I have not once had occasion to order a nutrient enema and have not once met with an untoward symptom in any of my cases.

It is a good plan to begin with a five- or six-ounce enema, increasing the bulk each time by one ounce until ten ounces are easily retained. I have not found it necessary to go beyond this. The enemata are given every four or six hours according to circumstances. In most cases it is possible to supplement the enemata by giving small quantities of peptonised milk by the mouth before the end of a week but in several instances my patients have had nothing whatever by the mouth for ten days or a fortnight, and in one or two cases for nearly three weeks, without making any complaint or giving any indication that they were any the worse for their prolonged abstinence. To sum up, the method here adrocated gives results at least as good as the ordinary mutrient enemata. It is far simpler to carry out, it is decidedly more bearable for the patient, and incidentally it does away with the unpleasant and offensive daily wash out.

The results obtained with enemata of plain water suggest some interesting reflections on the value of the foodstuffs of the ordinary nutrient enema and the absorptive power of the rectum but this is hardly the place to discuss these points.

Chandos-street, W.

\section{ANKYLOSTOMIASIS. ${ }^{1}$}

BY J. CHRONNELL, M.R.C.S. ENG., L.R.C.P. IREL., MEDICAI OFFICER OF HEALTH, HINDLEY URBAN DISTRICT COUNCII; PRESIDENT OF THE WIGAN MEDICAL SOCIETY.

THE subject of my paper is, it seems to me, one that must peculiarly appeal to a medical society situated in a colliery district. The disease ankylostomiasis is one that the majority of the members can know little of and that only from reading. I find in Taylor's " Medicine," sixth edition, 1901, that the disease is unknown in England and in the second edition of Quain's "Dictionary of Medicine" the same appears, so we err in good company. My own attention was first drawn to the matter about 12 months ago in connexion with the appearance of the disease in Cornwall and since then I have taken a deep interest in the subject and have done all I could to interest others. I take it we may at any time have to deal with the pest and those of us with colliery sick clubs will have to give freely their time and labour in curing the victims of the ailment. It is difficult to cure and the ankylostomum duodenale once introduced into a colliery is very difficult to destroy. In England the Government, the colliery proprietor, and the collier through his union have seriously taken up the subject. The Colliery Guardian sent a commissioner (Mr. Salter) to study the disease in Westphalia and his report is issued as a supplement and a second edition appeared about a month ago revised by Dr. Haldane. The latter was sent to Westphalia and Cornwall by the Home Office and his reports have been issued as blue-books. About three weeks ago the Home Office issued a memorandum on the mode of detection of the orum of ankylostomum duodenale.

You will notice the first paragraph begins: "It is considered by Dr. Haldane not improbable that worm disease already exists in other mines in Great Britain besides those which are infected in Cornwall." My own opinion, and I advance it in all humility, is that we have had it in our own district, if not present now, but that fortnnately for $u$ the ovum did not find a suitable nidus-viz, air, moisture, and a temperature over $60^{\circ} \mathrm{F}$. We have collieries here in which we could find some, if not all, of these requirements.

1 Presidential address read before the Wigan Medical Society on April 14th, 1904.
The ankylostomum is a nematode worm, the male being onethird of an inch long and the female about half an inch long; it infests the jejunum and not the duodenum. The female lays an enormous number of eggs which can only become larvæ after their discharge in the fæces. Then, wi h a high temperature, absence of sunlight, presence of oxygen, and moisture, the eggs hatch in a week, producing free larvæ. Experimentally it has been proved that ova and free unripe larva are, when swallowed, unable to develop into adult worms. In a matured stage they become productive on entering the small intestine. Antiseptics so far are of very little use. Deprived of oxygen or exposed to sunlight they die. In ordinary water they live for long periods but drying kills them at once. Dr. Stockman says they live for about six years. The human intestine is its only known host.

The symptoms of the disease are those of anæmia in a serious form: pallor, palpitation, dizziness, dyspncea on exertion, loss of appetite, and sometimes diarrhoea or melæna. In Cornwall an irritable pustular skin eruption, locally known as " bunches," has been found. Though not often fatal it will be easily understood why the afflicted are incapable of work. I ought to mention here that a great number of men have been found to be infested with the worm and yet show no symptoms of anæmia-a fact that tends to confirm my own impression that men returning from service in India, Egypt, and South Africa must have brought the worm here. It is recognised that these men constitute an almost equal danger with the others. Until very recently we were led to believe the pallor of the body was due to hæmorrhage and the worms sucking the blood from the intestine. Dr. Haldane and Dr. Boycott, in the Journal of Hygiene, prove that it is not so. Measurements made by them show the anæmia to be due to a great increase in the total volume of the blood with a corresponding dilution of the hæmoglobin and in consequence the fainting, dizziness, and palpitation are caused by the defective aeration of the tissues, and the heart in particular, the condition being analogous to that of poisoning by carbon monoxide.

I need not go into the treatment, which in Fingland has been thymol and in Germany male fern, though a number of other drugs have been tried. What we ought to do is to try to improve the sanitary conditions of our collieries. You all know that underground, with a very few exceptions, nothing is done. A collier is free to go where he likes. He fouls his hands and eats his food at his work and indeed often enough at home he will not wash them before taking his dinner. No one asks that he shall have a lavatory in his working place but he ought to have suitable pails placed at convenient points in and about the workings. The pails should be brought to the surface daily and their contents burned in the furnace, run into a cesspool, or spread on the land. A great number of closets, water-closets where possible, must be provided on the surface and possibly some day there may be a bath on the surface. In Germany every collier has to have a bath at the colliery and to change his working clothes for others before he is allowed to leave the works. Lastly, I contend that every colliery ought to have a supply of pure fresh water not only on the bank but in the pit. How many times have you seen wounds that have been washed with tea because no other fluid was to be had.

Hindley.

\section{TRANSPLANTATION OF TENDON FOR MUSCULO-SPIRAL PARALYSIS.}

By H. M. W. GRAY, M.B., C.M. ABerd., F.R.C.S. EDIN., SURGEON TO THE ABERDEEN ROXAL INFIRMARY.

THE following case presents some remarkable and interesting facts.

A boy, aged 16 years, fractured his right humerus and by a fall during convalescence the fracture was made compound. Thereafter the musculo-spiral nerve became included in the callus. To free this, operation was performed and apparently, judging from the resulting paralysis, the nerve must have been severed during the manipulations. Further operations were done to improve matters but without success. Two years after the last operation the boy came under my care. At that time musculo-spiral paralysis was complete. He 